\title{
A RETROSPECTIVE ANALYSIS OF CLINICAL PROFILE OF ADMITTED LEPROSY PATIENTS IN A TERTIARY CARE HOSPITAL OF GOA OVER A SIX YEAR PERIOD
}

\author{
Rakhi Ghodge1, Prachi Bhandare2, Pankaj Shukla³, Mayur Bhobe ${ }^{4}$ \\ ${ }^{1}$ Associate Professor, Department of Skin (DVL), Goa Medical College. \\ ${ }^{2}$ Lecturer, Department of Skin (DVL), Goa Medical College. \\ 3Professor and HOD, Department of Skin (DVL), Goa Medical College. \\ ${ }^{4}$ Senior Resident, Department of Skin (DVL), Goa Medical College.
}

\section{ABSTRACT}

Leprosy (Hansen's disease) is a chronic infectious disease caused by Mycobacterium leprae. It still continues to be a major health problem in many countries including India. Early diagnoses and prompt treatment is the corner stone in reducing the load of infection and morbidity caused by Hansen's disease.

\section{OBJECTIVE}

The objective of this study was to assess the clinical and epidemiological profile and asses the conditions that required inpatient care in patients of Hansen's disease over a period of 6 years between 2010 and 2016 in the Department of Skin, Goa Medical College.

\section{METHODS}

This was a descriptive, observational and retrospective study, in which data of admitted patients in a tertiary care hospital was collected over a period of six years (2010-2016) and was analysed for clinical and epidemiological profiles.

\section{RESULTS}

In our study, males outnumbered the females and age group of 20-50 years was maximally affected. Multibacillary cases were more frequent among the newly-detected cases with BL (Borderline Lepromatous) and LL (Lepromatous) being the commonest spectrum. Reactions (Type I and II), trophic ulcers and disabilities were the major cause of admissions and even included patients who had completed their chemotherapy.

\section{CONCLUSION}

In our study, we found that prevalence of multibacillary cases is still high. This is important as globally elimination of leprosy is highly aimed at. The importance of counselling and educating patients is important not only to adhere to treatment regimes, but also for early recognition of symptoms.

\section{KEYWORDS}

Hansen's, Multidrug Therapy, Disabilities.

HOW TO CITE THIS ARTICLE: Ghodge R, Bhandare P, Shukla P, et al. A retrospective analysis of clinical profile of admitted leprosy patients in a tertiary care hospital of Goa over a six year period. J. Evolution Med. Dent. Sci. 2016;5(72):5249-5252, DOI: $10.14260 /$ jemds/2016/1189

\section{INTRODUCTION}

Hansen's disease is a disabling infectious disease and is a major health problem in India owing to the chronic course and disabilities. The principal of reducing the load of infection is the corner stone of leprosy control. The present study was undertaken to know the clinical profile of admitted leprosy patients, causes of hospitalisations and to observe any changing trends in the state of Goa.

\section{MATERIALS AND METHODS}

This is a descriptive, observational and retrospective study in which data was collected over a period of six years from January 2010 to December 2015. The data of all admitted

Financial or Other, Competing Interest: None.

Submission 29-07-2016, Peer Review 22-08-2016,

Acceptance 29-08-2016, Published 07-09-2016.

Corresponding Author:

Dr. Mayur Bhobe,

Sriram, House No: $613 / e / d / c, S P A R C$,

Behind Chowgule College,

Cupangale, Fatorda-403602, Goa.

E-mail: mayur8509@gmail.com

DOI: $10.14260 /$ jemds/2016/1189 leprosy patients in the department of skin was collected from Medical Records Department of Goa Medical College. Subsequent admissions of the same patient were not considered to prevent duplication of records; instead, the details of number of admissions were recorded on initial proforma. All cases of leprosy (new, completed treatment, relapse) were included in the study and their records were entered into specially made proformas.

Patients were diagnosed clinically based on RidleyJopling classification. Slit-skin smear was done in all patients. Patients were classified as PB (paucibacillary) and MB (multibacillary) according to WHO guidelines and treated respectively. ${ }^{1}$ Skin biopsy findings in all patients were correlated with the clinical diagnosis of Hansen's disease.

The data collected was analysed for demographic profiles (age, sex, religion, and ethnicity), clinical classifications, therapy details, common disabilities encountered, common presenting complaints, slit-skin smear status and year-wise distribution of patients with respect to clinical spectrum.

\section{RESULTS}

We had total of 228 patients, out of which 116 (69\%) patients were newly diagnosed, 52 (31\%) patients were on Multidrug 
Therapy (MDT) and 60 (25\%) patients had completed therapy.

We had total of 173 (76\%) males and 55 (24\%) females. The age ranged from years 7 to 70 years.

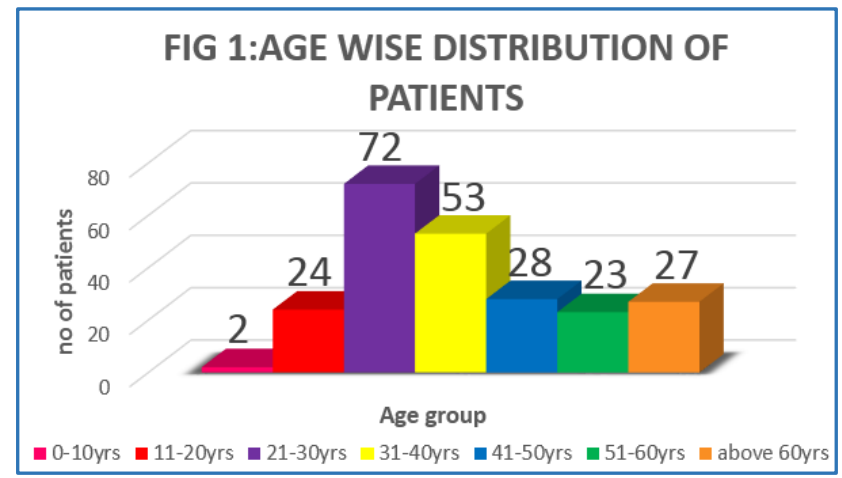

Majority of patients 116 (51\%) were migrants, while 112 (49\%) patients were natives of Goa. One hundred and seventy eight patients (78\%) were Hindus, $26(11 \%)$ patients belonged to Muslim community while Catholics comprised only $24(11 \%)$ patients.

\begin{tabular}{|c|c|c|c|}
\hline $\begin{array}{c}\text { Clinical } \\
\text { Spectrum }\end{array}$ & $\begin{array}{c}\text { On } \\
\text { Therapy }\end{array}$ & $\begin{array}{c}\text { Completed } \\
\text { Therapy }\end{array}$ & Total \\
\hline BT & $38(17 \%)$ & $16(7 \%)$ & 54 \\
\hline BB & $25(11 \%)$ & $9(4 \%)$ & 54 \\
\hline BL & $68(30 \%)$ & $24(10 \%)$ & 92 \\
\hline LL & $27(12 \%)$ & $10(4.3 \%)$ & 37 \\
\hline HISTOID & $1(0.4 \%)$ & 0 & 1 \\
\hline PNL & $9(4 \%)$ & $1(0.4 \%)$ & 10 \\
\hline \multicolumn{3}{|c|}{ Table 1: Detailed Clinical Spectrum } \\
of Patients Based on Therapy \\
\hline
\end{tabular}

*BT: Borderline Tuberculoid, +BB: Borderline Borderline, $\neq B L$ : Borderline Lepromatous, §LL: Lepromatous Leprosy, IPNL: Pure Neuritic Leprosy

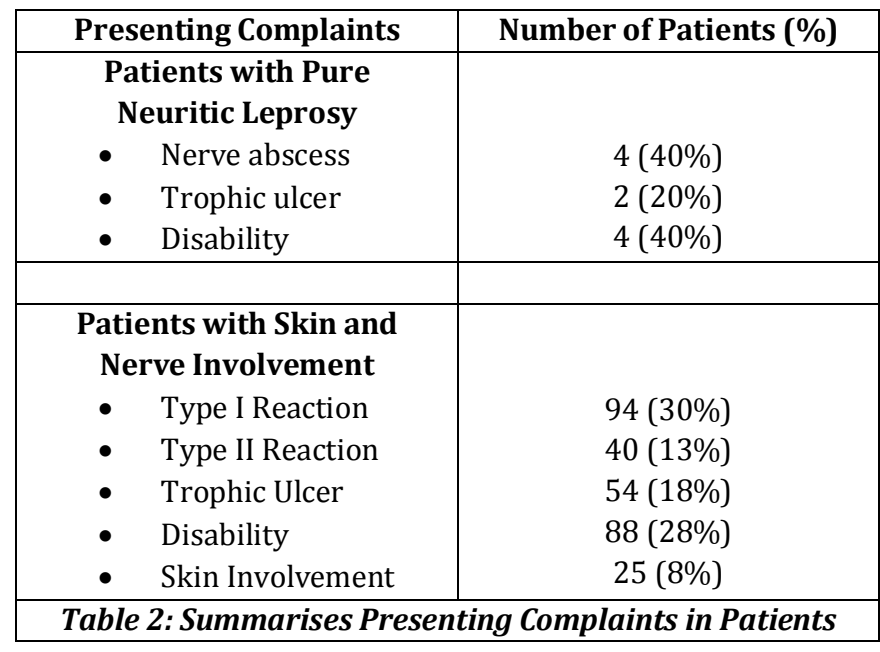

All patients of PNL had polyneuritic involvement. The presenting complaints comprised of FNAC proven nerve abscess in 4 (40\%) patients, trophic ulcers in 2 (20\%) patients and $4(40 \%)$ patients had disability.

In our study group, lepra reactions (type 1 and type 2) was the major cause of hospital admissions comprising of 94
(30\%) patients and $40(13 \%)$ patients, respectively. Eightyeight (28\%) patients had disabilities, while 54 (18\%) patients had trophic ulcers, which required in patient care. Predominant skin involvement including leprosy facies was seen in $25(8 \%)$ patients, while $9(3 \%)$ patients presented with nerve abscesses.

Eighty-two (36\%) patients had two presenting complaints at the time of presentation. Six patients in our study group had multiple (more than one) admissions during the study period. Recurrent lepra reactions and trophic ulcers being the commonest presenting complaints.

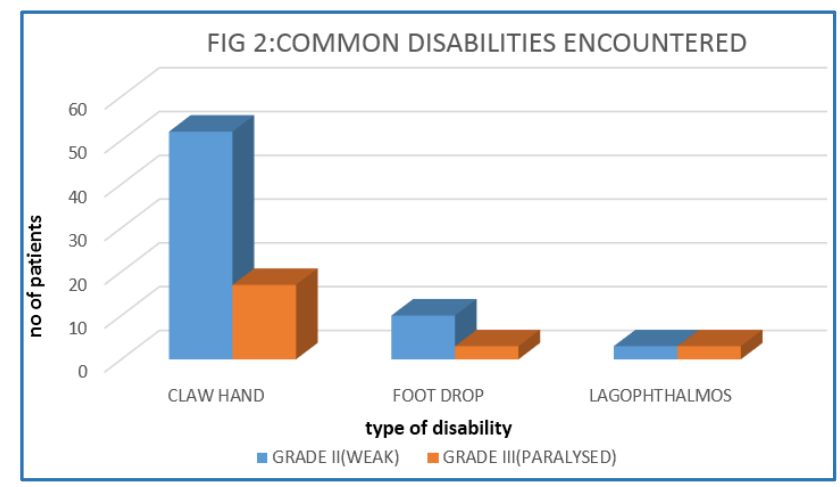

We had one patient who had bilateral claw hand while 2 (2\%) patients had two disabilities at the time of presentation. Among the patients with disabilities, $10(11 \%)$ patients had completed therapy (MDT), $35(40 \%)$ patients were on therapy and a majority of $43(49 \%)$ patients were newly diagnosed.

In an attempt to have a better understanding (to see for changing trends if any), we made a detailed year wise tabulation of newly-diagnosed patients with respect to clinical spectrum.

\begin{tabular}{|c|c|c|c|c|c|c|}
\hline Year & BT & BB & BL & LL & PNL & HISTOID \\
\hline 2010 & 2 & 3 & 4 & 1 & 0 & 0 \\
\hline 2011 & 3 & 2 & 3 & 3 & 2 & 0 \\
\hline 2012 & 3 & 4 & 6 & 0 & 0 & 0 \\
\hline 2013 & 4 & 4 & 9 & 8 & 1 & 1 \\
\hline 2014 & 5 & 1 & 16 & 8 & 2 & 0 \\
\hline 2015 & 5 & 4 & 7 & 4 & 1 & 0 \\
\hline Total & $\mathbf{2 2}$ & $\mathbf{1 8}$ & $\mathbf{4 5}$ & $\mathbf{2 4}$ & $\mathbf{6}$ & $\mathbf{1}$ \\
\hline \\
Table 3: Shows the Year Wise Tabulation of Newly- \\
Diagnosed Patients Based on Clinical Spectrum \\
\hline
\end{tabular}

\section{DISCUSSION}

Our study shows that patients in productive phase of life in age group of 20-50 years (young adults and middle aged) were more affected as compared to extremes of ages. This segment of the population is economically as well as socially active group of the society. Hansen's disease is a chronic disease and the course can be further complicated with reactional states and disabilities, which may require admission thereby affecting the working capacity of the individual. All these affect productivity of individuals and can have a negative impact on society and generate high social cost.2,3,4 The prevalence of leprosy in children is a useful indicator of the status of transmission of the disease in a country. ${ }^{5}$ The occurrence of multibacillary forms of disease is not a rarity in the Indian scenario, which is responsible for 
continuous transmission in society. Hence, detection in this age group can be considered as greater indicator of endemicity of the disease. Our study had 26 patients in the age group of 0-20 years out of which only two patients were in 0-10 age group. Similar findings were found in study conducted by Bhat et al who found only 7 (15.22\%) of patients in under 15 year age group. ${ }^{3}$ As in our study, they found the maximum prevalence of leprosy in 36 to 50 year age group. A study conducted in Brazil by Sousa et al who found that individuals under 15 years of age constituted a small minority of patients (8.55\%). ${ }^{6}$ However, this may not predict the actual childhood cases as our study involved only admitted patients thereby eliminating cases that did not have complications.

In our study, males outnumbered females. Predisposition in males was also seen in studies conducted by Thakker et al and Bhat et al2,3,6,7 However, a greater access of females to healthcare is showing an increased reporting in this gender group. In recent years, the state of Goa has witnessed rapid urbanisation. This is associated with increased influx of migrant population mostly young males for better job prospects leaving their family members behind. In our study, migrant population were more affected than natives of this state. This group comprised largely of individuals in lower socioeconomic strata working as daily wage workers thereby factors like nutrition, crowding index, personal hygiene may play an important contributory role. Unlike the migrant population where predominantly the lower socioeconomic group were affected, we found that in native population of the state it was equally prevalent in all sections of society. Out of 228 patients in our study group, 60 (26\%) patients had already completed their therapy, but still required inpatient care owing to complications. This further highlights the fact that these complications pose financial constraints and affect productivity of affected individuals thereby associating the disease with stigma.

Out of 168 patients who were on therapy, 38 (23\%) were paucibacillary (BT group) and $9(6 \%)$ were PNL while the remaining $121(71 \%)$ patients belonged to multibacillary group (BB, BL, LL).

This is in contrast to previous studies conducted by Bhat et al and Thakker et al.2,3 The predominance of lepromatous leprosy in our study could be due to delay in seeking medical attention among the migrant population. Pure neuritic type was the least common type in all the studies.

In our study, the major cause of admission was lepra reactions (type I and type II) followed by disabilities and trophic ulcers. Only four patients with nerve abscess were admitted. Type I reactions were more common than type II reactions. This was in accordance with study conducted by Bhat et $\mathrm{al}^{3}$ On the contrary, higher incidence of type 2 reactions was seen in studies conducted by Thakker et al and Salodkar and Kalla. ${ }^{8}$

Deformities and disabilities are a major problem in Hansen's disease as they have a great impact on the life of patients affected. Although, they can occur in any subset of patients, delay in diagnosis and treatment, inadequate knowledge of hand and foot care, multibacillary form of disease, severe clinical diseases and frequent reactional episodes are the predisposing factors.9,10 In our study, claw hand was the commonest seen in $69(78 \%)$ patients followed by foot drop in 13 (15\%) patients and lagophthalmos in 6
(7\%) patients. Out of the 88 patients who had disabilities, 43 (48\%) patients were newly diagnosed thereby highlighting the importance of early and timely diagnosis. Of the patients who developed disabilities, $10(11 \%)$ had completed therapy and developed disabilities later as part of reactional state while 35 (39\%) were on therapy. Hence, the importance of counselling patients, educating them for early recognition of symptoms and prompt treatment cannot be over emphasised.

Among the patients of PNL, an interesting fact that we noted was that this form of disease is also prone to reactional states. In one of our patients, skin lesions became apparent 7 months after MBMDT similar to previous studies by Jacob et al and Girdhar et al ${ }^{11,12}$ It is possible that PNL could be a forme fruste of the disease and hence these patients need to be followed on long-term basis to see for any skin involvement.

In order to see for any changing trends, we tabulated year wise categorisation of patients. An alarming trend that we found was that the number of multibacillary cases (BB, BL, LL) were on rise from 2012 onwards with age of more than 20 years being predominantly affected and BL spectrum being the commonest. A rapid influx of migrant population could be the possible explanation. Out of 116 (51\%) newlydiagnosed patients, 94 (81\%) patients were multibacillary and $22(18 \%)$ were paucibacillary.

All multibacillary patients had a positive slit-skin smear, which highlights the importance of this test as a valuable tool for aiding in diagnosis beside histopathology.

The limitation of our study was that it was restricted to inpatients only.

\section{CONCLUSIONS}

Leprosy is a chronic infectious disease associated with social stigma owing to its deformities. We found a high prevalence of multibacillary cases in our study. The multibacillary form of disease requires in patient care.

Our study points out to the fact that the prevalence of multibacillary cases is still high. This is important especially in a scenario where elimination of leprosy is highly aimed at.

Early diagnoses, prompt treatment and adequate patient counselling remains crucial in reducing load of infection.

\section{REFERENCES}

1. Chemotherapy of leprosy for control programmes. World Health Organ Tech Rep Ser. 1982;675:1-33.

2. Thakkar S, Patel SV. Clinical profile of leprosy patients: a prospective study. Indian J Dermatol 2014;59(2):158-62.

3. Bhat RM, Chaitra P. Profile of new leprosy cases attending a south Indian referral hospital in 2011-2012. ISRN Tropical Medicine. Article ID 579024, 2013;2013: 1-4.

4. Quyum F, Hasan M, Chowdhury WK, et al. Epidemiological indicators and clinical profile of leprosy cases in Dhaka. Journal of Pakistan Association of Dermatologists 2015;25(3):191-6.

5. Palit A, Inamadar AC. Childhood leprosy in India over the past two decades. Lepr Rev. 2014;85(2):93-9.

6. Sousa MW, Silva DC, Carneiro LR, et al. Epidemiological profile of leprosy in the Brazilian state of Piaui between 2003 and 2008. An Bras Dermatol 2012;87(3):389-95.

7. Tiwary PK, Kar HK, Sharma PK, et al. Epidemiological trends of leprosy in an urban leprosy centre of Delhi: a 
retrospective study of 16 years. Indian J Lepr. 2011; 83(4):201-8.

8. Salodkar AD, Kalla G. A clinico-epidemiological study of leprosy in arid north-west Rajasthan, Jodhpur. Indian J Lepr. 1995;67(2):161-6.

9. Scollard DM, Truman RW, Ebenezer GJ. Mechanism of nerve injury in leprosy. Clin Dermatol. 2015;33(1): 46-54.
10. Kar HK, Gupta R. Treatment of leprosy. Clin Dermatol. 2015;33(1):55-65.

11. Jacob M, Arunthathi S. The Wague. A study primary neuritic leprosy (Abst): In Proc XIII Int Lep Congr (September 11-17) 1988:313.

12. Girdhar BK. Neuritic leprosy. Indian J Lepr. 1996;68 (1):35-42. 